\title{
PEDIATRIC FLEXIBLE VALGUS FLATFOOT CORRECTION BY ARTHROEREISIS
}

\section{CORREÇÃO DE PÉ PLANO VALGO FLEXÍVEL PEDIÁTRICO POR ARTRORRISE}

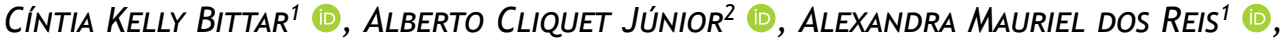

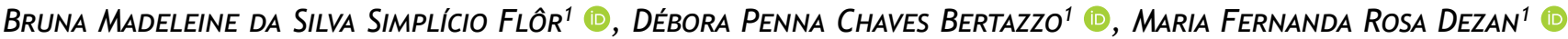

1. Pontifícia Universidade Católica de Campinas, Campinas, SP, Brazil.

2. Universidade Estadual de Campinas, Campinas, SP, Brazil.

\section{ABSTRACT}

Objective: This article aimed to evaluate the efficacy of arthroereisis using synthetic polyethylene implants to correct excessive valgus deformity in pediatric patients with flexible valgus flatfoot. Methods: Retrospective study of 20 pediatric patients with flexible valgus flatfoot, totaling 23 feet, between five and 14 years old, operated between January 2009 and July 2016. Clinical evaluations were performed by the Valenti podoscopic classification and the American Orthopaedic Foot \& Ankle Society criteria, based on radiographic images and podoscopic analysis. These patients underwent surgical treatment with the introduction of a synthetic implant in the sinus tarsi. Multiple linear regression analysis with Backward selection of variables, angles of pre and postoperative of radiographic images of the patients submitted to arthroereisis were performed. Results: The arthroereisis with interposition of synthetic material was satisfactory, considering that $91 \%$ of the cases presented clinical and radiographic improvement, with correction of angles and improvement in deformity degrees. Two cases presented implant loosening. The variables of the Bordelon and Pitch angles significantly influenced $(p<0,05)$ the improvement of the correction of deformity degrees. Conclusion: The arthroereisis with the interposition of synthetic polyethylene material showed to be an effective technique for flexible flatfoot in symptomatic pediatric patients. Level of Evidence II, Prognostic studies - Investigating the Effect of a Patient Characteristic on the Outcome of Disease.

Keywords: Prostheses and Implants. Flatfoot. Orthopedic Procedures.

\section{RESUMO}

Objetivo: Este artigo teve como objetivo avaliar a eficácia da artrorrise utilizando implantes sintéticos de polietileno para corrigir a deformidade em valgo excessivo em pacientes pediátricos com pé plano valgo flexível. Métodos: Estudo retrospectivo de 20 pacientes pediátricos com pé plano valgo flexível, sendo 23 pés, de cinco a 14 anos de idade, operados entre 2009 e 2016. Avaliações clínicas foram realizadas pela classificação podoscópica de Valenti e os critérios da American Orthopaedic Foot \& Ankle Society. Esses pacientes foram submetidos a tratamento cirúrgico com a introdução de um implante sintético no seio do tarso. Foi realizada análise de regressão linear múltipla com seleção Backward das variáveis, os ângulos do pré e pós-operatórios das imagens radiográficas dos pacientes submetidos à artrorisse. Resultados: A artrorrise com interposição de material sintético foi satisfatória considerando que $91 \%$ dos casos apresentaram melhora clínica e radiográfica, com correção de ângulos e melhora nos graus de deformidade. Dois casos apresentaram afrouxamento do implante. As variáveis dos ângulos de Bordelon e Pitch influenciaram significativamente $(p<0,05)$ na melhora da correção dos graus de deformidade. Conclusão: A artrorrise com interposição de material sintético de polietileno mostrou-se uma técnica eficaz para pé plano flexível em pacientes pediátricos sintomáticos. Nível de Evidência II, Estudos prognósticos Investigação do efeito de característica de um paciente no desenvolvimento da doença.

Descritores: Próteses e Implantes. Pé Chato. Procedimentos Ortopédicos.

Citation: Bittar CK, Cliquet A Jr, Reis AM, Flôr BMSS, Bertazzo DPC, Dezan MFR. Pediatric flexible valgus flatfoot correction by arthroereisis. Acta Ortop Bras. [online]. 2020;28(4):212-215. Available from URL: http://www.scielo.br/aob.

\section{INTRODUCTION}

Flexible valgus flatfoot (FVFF) is one of the most common orthopedic pathologies in children. ${ }^{1}$ Most patients do not present any symptomatology, referring only diffuse and poorly located pains when walking long distances and during physical activities. These pains can occur in the foot or extend to the ankle or leg. ${ }^{2}$

All authors declare no potential conflict of interest related to this article.

The study was conducted at the Pontifícia Universidade Católica de Campinas Hospital and has a contribution from the first author's archive.

Correspondence: Alexandra Mauriel dos Reis. Rua José Rocha Bonfim, 214, ed. Chicago, 1o andar, cond. Praça Capital, Campinas, SP, Brazil, 13080-650. ale.reis10@hotmail.com 
It is believed that children with FVFF who do not receive any treatment may develop some secondary deformity, such as postural deviations. ${ }^{3}$ The evolution of the condition can generate hallux valgus, metatarsalgia, tarsal tunnel syndrome, posterior tibial tendon dysfunction and osteoarthritis, mainly on subtalar joint. ${ }^{4,5}$

The most evident changes for FVFF are the loss of medial longitudinal arch, plantar flexion of the talus in relation to the calcaneus, medial and plantar prominence of the talar head, forefoot abduction at the talonavicular joint and calcaneus valgus. ${ }^{6}$ In addition to these modifications, FVFF is classified by degrees, depending on the deformities presented. The podoscopic analysis described by Valenti considers five grades (from Grade I to Grade V), depending on the severity of the deformity.

The surgical indication in FVFF cases is a discussed subject. ${ }^{5}$ Generally, when surgical treatment is indicated, it must be performed in patients between eight and 14 years old, with pain or other limitations. ${ }^{8}$ In the literature, satisfactory clinical results can be observed for arthroereisis in pediatric patients. ${ }^{1,4,9}$

Arthroereisis represents one of the most commonly used procedures in pediatric patients with FVFF in Europe. ${ }^{9,10}$ Above all, it becomes an interesting alternative for being minimally invasive ${ }^{10}$ when compared to other surgical procedures, such as tendon lengthening and tendon transfer, bone excisions, osteotomies, arthrodesis, and interposition of bone or synthetic material in the sinus tarsi.

The arthroereisis of the subtalar joint reduces, without totally eliminating, joint movement. It promotes the neutralization of the foot abnormal pronation, corrects the calcaneus valgus and increases the medial longitudinal arch in the growing child, where the implant placement in the sinus tarsi limits the anterior and medial displacement of the talus. ${ }^{11,12}$ It provides a quick recovery with little postoperative immobilization and preservation of the joint functional movement, with $85 \%$ of good results. ${ }^{5,13}$

Considering the cases of surgical indication in pediatric patients with FVFF refractory to conservative treatment, this study aims to evaluate the effectiveness of arthroereisis using a synthetic polyethylene implant as method to correct excessive valgus deformity in pediatric patients with flexible flatfoot, based on the improvement of degrees of deformity according to Valenti's classification.

\section{MATERIALS AND METHODS}

The study was approved by the Research Ethics Committee under CAAE number: 90459018.0.0000.5599

The study was performed with 20 pediatric patients with symptomatic FVFF between five and 14 years old at the time of surgery. Patients had symptoms that consisted of foot pain during daily activities, foot pain during or after sports, or early muscle fatigue during weight-bearing sports activities. Furthermore, these patients were considered to be refractory to conservative treatment, with no satisfactory response after the use of insoles, non-steroidal anti-inflammatory drugs and/or treatment with physiotherapy for stretching and strengthening of the extrinsic and intrinsic musculature of the feet.

Clinical evaluations were performed using the American Orthopaedic Foot \& Ankle Society (AOFAS) criteria, based on radiographic images and podoscopic analysis according to Valenti's classification. In this case, according to Valenti's classification, those patients who presented grade III (midfoot width exceeding forefoot width) and grade IV (bulging of medial edge - semilunate image) were selected for the surgical procedure.

The following angles and lines were also considered in radiographs of the anterior-posterior (AP) and foot profile, with load, being: $20-40^{\circ}$ of talocalcaneal axis (Kite $>40^{\circ}$ in flatfoot) considered normal and $60-80^{\circ}$ of talonavicular axis (Bordelon), considered normal for AP. The talo-first metatarsal axis (Meary), the normal being zero; $15-20^{\circ}$ of inclination axis of the calcaneus (calcaneal pitch angle $<15^{\circ}$ in the flat foot), being the normal; axis of plantar flexion of the talus (talus pitch angle, increased in the flatfoot), being the normal $26^{\circ} \pm 5^{\circ}$ and the talocalcaneal axis (Kite $>50^{\circ}$ in the flatfoot), being normal $35-50^{\circ}$ in the profile.

After a careful analysis of the factors, patients underwent surgical treatment by arthroereisis with the introduction of a synthetic implant (polyethylene conical screw) in the sinus tarsi between January 2009 and July 2016

The technique consisted of inserting the guide wire through the sinus tarsi, about $15^{\circ}-20^{\circ}$ from the perpendicular to the sagittal plane, anterolateral to the postero-medial, leaving below the posterior tibial tendon (Figure 1).

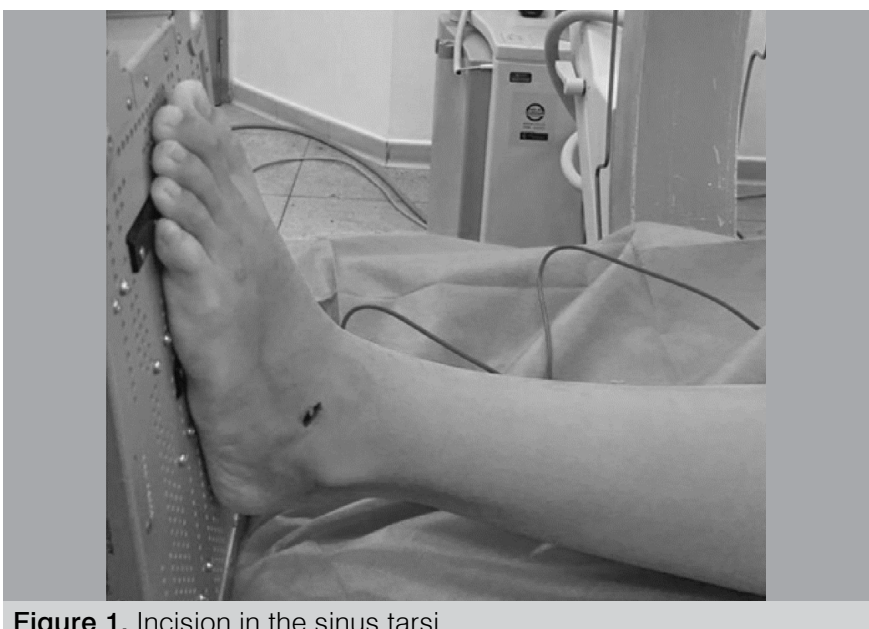

Figure 1. Incision in the sinus tarsi.

A test sizer was inserted into the guide wire and initial evaluation was performed to verify the eversion of the calcaneus. Once the proper insertion distance was verified in the fluoroscopy, distance was confirmed using laser marks in the driver and comparison with the skin line. The lateral border of the implant was located in the middle or medial to the lateral side of the talus (Figure 2).

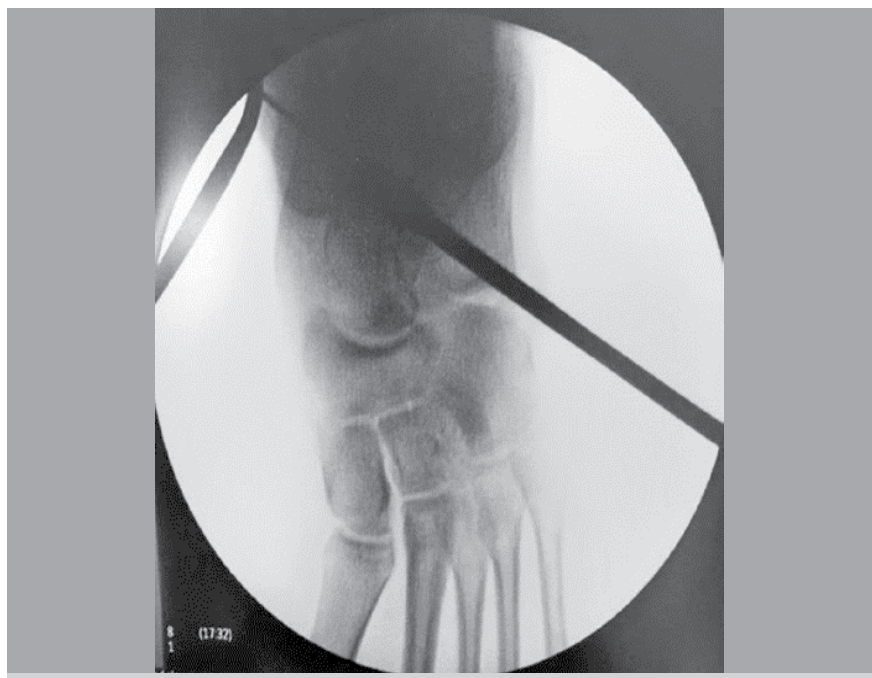

Figure 2. Insertion of the guide wire through the sinus tarsi.

After the surgical procedure, pre and postoperative radiographs were analyzed, comparing Bordelon, Kite, Gould, Meary and Pitch $X$-ray angles in anterior-posterior and foot profile, with load, with the 
aid of the goniometer and podoscopic analysis. This information enabled the assessment of the FVFF degree and the exact correction of the deformity (Figure 3).
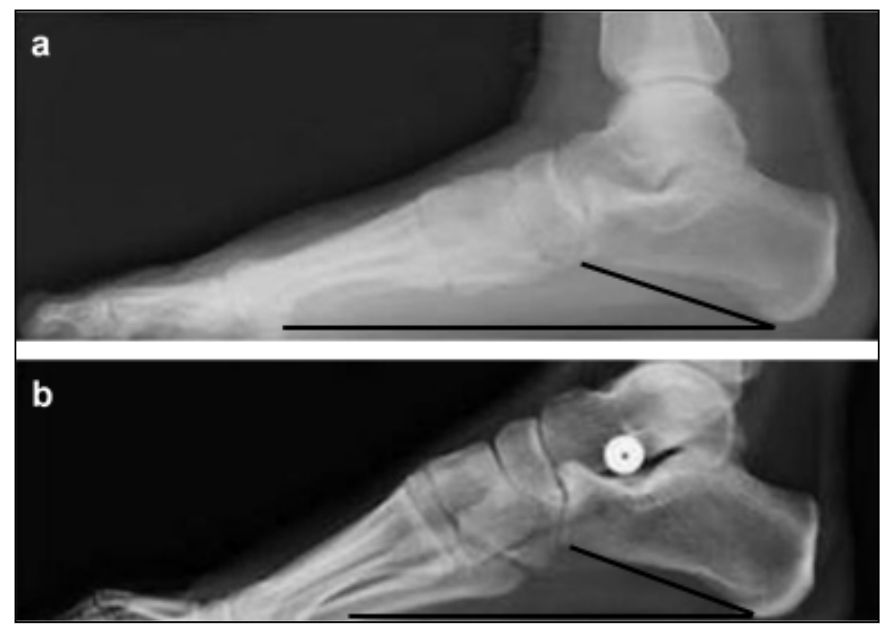

Figure 3. Preoperative (a) and postoperative (b) radiographic image of pediatric patient with flexible valgus flatfoot submitted to arthroereisis with implant of synthetic polyethylene material. We can observe an increase in the calcaneal pitch angle.

Therefore, we used the preoperative variables Valenti's classification, Bordelon, Kite, Gould, Meary and Pitch angles of pre and postoperative radiographic images of the patients to verify the predictive power over the response variable, in other words, the efficiency of arthroereisis in FVFF to improve the degree of deformity, by the classification of Valenti. Thus, multiple linear regression analysis with Backward selection of variables was used. The statistical analyses were performed with the aid of R Core Team software (2017). ${ }^{14}$

\section{RESULTS}

A total of 20 patients with FVFF were analyzed, of which three received bilateral procedure, totaling 23 feet, with a mean age of 8.13 years old. The average postoperative follow-up was 33 months (ranging between 24 and 43 months). In all patients the synthetic polyethylene implant was used.

Among the operated feet, two presented loosening of the implant, which had to be removed by a second surgery. In these cases, there was no correction of the Bordelon, Kite and Meary angles and the angles of Gould, Pitch and deformity degree by the Valenti's classification (Grade IV) remained unchanged (Table 1).

The arthroereisis with interposition of synthetic material was satisfactory, considering that 21 feet ( $91 \%$ of the cases) presented clinical and radiographic improvement, with correction of the angles and improvement in the deformity degrees by Valenti's classification. It was observed that the Bordelon, Kite and Meary angles decreased by a mean of $6,75^{\circ}, 10,5^{\circ}$ and $7,5^{\circ}$, respectively. The calcaneal pitch increased by an average of $6,7^{\circ}$ (Figure 3 ) and the talonavicular coverage angle (Gould) increased by $1,9 \mathrm{~mm}$. The mean correction was $7^{\circ}$ for the calcaneal pitch, one and two $\mathrm{mm}$ for the Gould, $9^{\circ}$ for the Bordelon and Kite angles, $9^{\circ}$ and $6^{\circ}$ for the Meary (Table 1). We also observed the improvement in deformity degrees based on Valenti's classification. From five feet evaluated as grade III, four improved to grade II and one improved to grade I. From the 18 feet evaluated as grade IV, five improved to grade III and 11 improved to grade II (Table 1).

By the Backward regression model, the variables of the Bordelon and Pitch angles significantly influenced $(p<0,05)$ the improvement of the correction in deformity degrees based on the Valenti's classification. The obtained model presented correlation of $64 \%$, demonstrating the relation between the variables.

The score obtained in AOFAS criteria was 73 points in preoperative period and 92 points in postoperative period. Two patients were unsatisfied due to the screw looseness.

Table 1. Evolution of the radiological parameters, Valenti podological classification, American Orthopaedic Foot \& Ankle Society criteria, and pre and postsurgical procedure for flexible flatfoot correction by arthroereisis in pediatric patients between 5 and 12 years of age.

\begin{tabular}{|c|c|c|c|c|c|c|c|c|c|}
\hline & & & Bordelon angle & Kite angle & Gould angle & Meary angle & Pitch angle & Valenti classification & AOFAS criteria \\
\hline & Age & Sex & \begin{tabular}{|l|} 
Pre/post surg. \\
\end{tabular} & Pre/post surg. & Pre/post surg. & Pre/post surg. & Pre/post surg. & Pre/post surg. & Pre/post surg. \\
\hline Foot 1 & 7 & $M$ & $17-18^{\circ}$ & $48-51^{\circ}$ & $8-8 \mathrm{~mm}$ & $21-24^{\circ}$ & $12-12^{\circ}$ & Grade IV-IV & $69-80$ \\
\hline Foot 2 & 12 & $M$ & $20-12^{0}$ & $43-35^{\circ}$ & $8-5 \mathrm{~mm}$ & $18-11^{\circ}$ & $10-16^{0}$ & Grade IV-II & $70-97$ \\
\hline Foot 3 & 8 & $\mathrm{~F}$ & $19-15^{\circ}$ & $50-41^{\circ}$ & $7-6 \mathrm{~mm}$ & $22-17^{0}$ & $8-12^{0}$ & Grade III-II & $70-94$ \\
\hline Foot 4 & 8 & $\mathrm{~F}$ & $22-18^{\circ}$ & $54-49^{\circ}$ & $9-7 \mathrm{~mm}$ & $25-19^{\circ}$ & $8-13^{\circ}$ & Grade IV-II & 73-97 \\
\hline Foot 5 & 6 & $M$ & $28-18^{\circ}$ & $58-46^{\circ}$ & $9-5 \mathrm{~mm}$ & $26-17^{0}$ & $9-16^{\circ}$ & Grade IV-III & $70-95$ \\
\hline Foot 6 & 5 & $\mathrm{~F}$ & $20-15^{\circ}$ & $55-40^{\circ}$ & $7-4 \mathrm{~mm}$ & $17-10^{\circ}$ & $10-18^{\circ}$ & Grade III-II & $78-92$ \\
\hline Foot 7 & 7 & $M$ & $22-13^{\circ}$ & $61-41^{\circ}$ & $7-5 \mathrm{~mm}$ & $20-14^{\circ}$ & $9-17^{\circ}$ & Grade IV-II & $75-96$ \\
\hline Foot 8 & 10 & $M$ & $28-20^{\circ}$ & $62-40^{\circ}$ & $7-4 \mathrm{~mm}$ & $27-17^{0}$ & $7-13^{\circ}$ & Grade IV-II & $71-97$ \\
\hline Foot 9 & 8 & $\mathrm{~F}$ & $17-12^{\circ}$ & $42-38^{\circ}$ & $6-5 \mathrm{~mm}$ & $18-15^{\circ}$ & $10-14^{\circ}$ & Grade III-I & $76-97$ \\
\hline Foot 10 & 9 & $M$ & $23-16^{\circ}$ & $56-41^{\circ}$ & $8-5 \mathrm{~mm}$ & $19-14^{\circ}$ & $12-19^{\circ}$ & Grade IV-III & $74-89$ \\
\hline Foot 11 & 6 & $M$ & $23-14^{\circ}$ & $50-41^{\circ}$ & $7-5 \mathrm{~mm}$ & $26-14^{\circ}$ & $8-14^{\circ}$ & Grade IV-II & 73-95 \\
\hline Foot 12 & 8 & $\mathrm{~F}$ & $28-20^{\circ}$ & $55-42^{\circ}$ & $8-5 \mathrm{~mm}$ & $28-16^{\circ}$ & $7-18^{\circ}$ & Grade IV-III & $75-88$ \\
\hline Foot 13 & 7 & $\mathrm{~F}$ & $30-16^{\circ}$ & $47-39^{\circ}$ & $7-5 \mathrm{~mm}$ & $31-16^{\circ}$ & $10-19^{\circ}$ & Grade IV-III & $70-87$ \\
\hline Foot 14 & 8 & $\mathrm{~F}$ & $32-18^{\circ}$ & $50-41^{\circ}$ & $7-6 \mathrm{~mm}$ & $28-18^{\circ}$ & $9-16^{\circ}$ & Grade IV-II & $72-98$ \\
\hline Foot 15 & 9 & $M$ & $27-15^{\circ}$ & $49-38^{\circ}$ & $8-6 \mathrm{~mm}$ & $31-18^{\circ}$ & $11-18^{\circ}$ & Grade IV-II & $74-97$ \\
\hline Foot 16 & 9 & $M$ & $26-16^{\circ}$ & $53-41^{\circ}$ & $8-7 \mathrm{~mm}$ & $29-20^{\circ}$ & $10-18^{\circ}$ & Grade IV-II & $75-97$ \\
\hline Foot 17 & 7 & $M$ & $30-19^{\circ}$ & $50-43^{\circ}$ & $7-6 \mathrm{~mm}$ & $27-21^{\circ}$ & $9-16^{0}$ & Grade IV-II & $67-99$ \\
\hline Foot 18 & 6 & $\mathrm{~F}$ & $28-18^{\circ}$ & $58-46^{\circ}$ & $9-5 \mathrm{~mm}$ & $26-17^{\circ}$ & $9-16^{\circ}$ & Grade IV-III & $78-90$ \\
\hline Foot 19 & 10 & $M$ & $20-15^{\circ}$ & $55-40^{\circ}$ & $7-4 \mathrm{~mm}$ & $17-10^{\circ}$ & $10-18^{\circ}$ & Grade III-II & $74-90$ \\
\hline Foot 20 & 12 & $M$ & $16-18^{\circ}$ & $47-52^{\circ}$ & $7-7 \mathrm{~mm}$ & $22-24^{\circ}$ & $11-11^{0}$ & Grade IV-IV & $68-79$ \\
\hline Foot 21 & 9 & $\mathrm{~F}$ & $20-12^{\circ}$ & $43-35^{\circ}$ & $8-5 \mathrm{~mm}$ & $18-11^{\circ}$ & $10-16^{\circ}$ & Grade IV-II & $70-93$ \\
\hline Foot 22 & 8 & $\mathrm{~F}$ & $19-15^{\circ}$ & $50-41^{\circ}$ & $7-6 \mathrm{~mm}$ & $22-17^{\circ}$ & $8-12^{\circ}$ & Grade III-II & 73-93 \\
\hline Foot 23 & 8 & $\mathrm{~F}$ & $22-18^{\circ}$ & $54-49^{\circ}$ & $9-7 \mathrm{~mm}$ & $25-19^{\circ}$ & $8-13^{\circ}$ & Grade IV-II & $74-90$ \\
\hline
\end{tabular}




\section{DISCUSSION}

Flexible flatfoot is a relatively common alteration in pediatric patients, diagnosed in $10 \%$ of the children.1,15 The indication of surgical treatment in a child is based on the conjunction of symptoms, morphological criteria and failure of conservative treatment well conducted for at least six months. ${ }^{16}$

The ideal age for surgery is widely debated. Several authors justify the surgical indication for children between eight and 14 years old, due to clinical signs such as fatigue, cramps or activity limitation., ${ }^{1,4,9}$ In this study, surgery was performed on a five-year-old patient. There is substantial variation in age between studies, some including children from two to six years old. ${ }^{17,18}$ In these cases, bone maturity should be considered. ${ }^{1,18}$ Considering that the foot is physiologically flat up to the age of four and then gradually transformed into a helical structure.

The results of the study showed that the arthroereisis in cases of symptomatic flexible valgus flatfoot with the interposition of synthetic material in the sinus tarsi were satisfactory. The efficacy of this procedure has been reported by several studies in literature, with an average follow-up time.16,19

In this study, it was possible to observe excellent results in relation to the polyethylene implant used, considering that in only two cases $(8.69 \%)$ the removal of the material was required. Similar results to those were found by Faldini et al., ${ }^{4,19}$ with the use of a synthetic bio-absorbable implant.

Some studies ${ }^{9,20}$ have shown that even the implant being prematurely removed, the foot position was maintained with a certain degree of correction, which enabled good clinical results. This fact corroborates our findings, in which patients who had loosening of implants, even with implant removal, did not report other postoperative changes, complications such as pain or difficulty to walk. Arthroereisis is a good alternative to osteotomies and arthrodesis for the treatment of symptomatic flexible valgus flatfeet refractory to clinical treatment. The benefits of this technique include ease execution, little or none interference with osteoarticular tissue of the sinus tarsi, it does not hinder other surgical options in the future, less surgical morbidity, faster return to rehabilitation, and stabilization of the subtalar joint (considering the principle of correction of the initial deformity in valgus plane).

\section{CONCLUSION}

Surgical treatment by arthroereisis with the interposition of synthetic polyethylene material in the sinus tarsi showed to be a simple, minimally invasive, and effective technique for flexible flatfoot in symptomatic pediatric patients, with a low complication rate, important clinical improvement, and high degree of satisfaction.

AUTHORS' CONTRIBUTIONS: Each author contributed individually and significantly to the development of this article. CKB: conception and design of the study, data acquisition, analysis and interpretation, drafting the article and approval of the final version; ACJ: conception and design of the study, AMR: conception and design of the study, drafting the article, revising it critically for important intellectual content and approval of the final version; BMSSF: conception and design of the study, drafting the article, revising it critically for important intellectual content and approval of the final version; acquisition, data analysis and interpretation, drafting the article and approval of the final version; DPCB: conception and design of the study, drafting the article, revising it critically for important intellectual content and approval of the final version; MFRD: conception and design of the study, drafting the article, revising it critically for important intellectual content and approval of the final version.

\section{REFERENCES}

1. Giannini BS, Ceccarelli F, Benedetti MG, Catani F, Faldini C. Surgical treatment of flexible flatfoot in children: a four-year follow-up study. J Bone Joint Surg Am. 2001;83-A Suppl 2 Pt 2:73-9.

2. Corte-Real N, Felicíssimo P. Pé plano infantil. Acta Ped Port. 1995;26(4):191-6.

3. Smith SD, Millar EA. Arthrorisis by means of a subtalar polyethylene peg implant for correction of hindfoot pronation in children. Clin Orthop Relat Res. 1983;(181):15-23.

4. Faldini C, Nanni M, Traina F, Fabbri D, Borghi R, Giannini S. Surgical treatment of hallux valgus associated with flexible flatfoot during growing age. Int Orthop. 2016;40(4):737-43.

5. Faldini C, Mazzotti A, Panciera A, Perna F, Stefanini N, Giannini S. Bioabsorbable implants for subtalar arthroereisis in pediatric flatfoot. Musculoskelet Surg. 2018;102:11-9.

6. Scher DM, Bansal M, Handler-Matasar S, Bohne WH, Green DW. Extensive implant reaction in failed subtalar joint arthroereisis: report of two cases. HSS Jrnl. 2007;3(2):177-81.

7. Crawford AH, Kucharzyk D, Roy DR, Bilbo J. Subtalar stabilization of the planovalgus foot by staple arthroereisis in young children who have neuromuscular problems. J Bone Joint Surg Am. 1990;72(6):840-5.

8. Giannini S. Operative treatment of the flatfoot: why and how. Foot Ankle Int 1998; 19(1):52-8

9. Giannini S, Cadossi M, Mazzotti A, Persiani V, Tedesco G, Romagnoli M, et al. Bioabsorbable calcaneo-stop implant for the treatment of flexible flatfoot: a retrospective cohort study at a minimum follow-up of 4 years. J Foot Ankle Surg. 2017;56(4):776-82.

10. Pavone V, Costarella L, Testa G, Conte G, Riccioli M, Sessa G. Calcaneo-stop procedure in the treatment of the juvenile symptomatic flatfoot. J Foot Ankle Surg. 2013;52(4):444-7.
11. Koning PM, Heesterbeek PJ, de Visser E. Subtalar arthroereisis for pediatric flexible pes planovalgus. J Am Podiatr Med Assoc. 2009;99(5):447-53.

12. Rossi C. A incidência de pé cavo, plano e normal em indivíduos com classe I, II e III de Angle [dissertation]. Cascavel: Faculdade Assis Gurgacz; 2006. 91 p.

13. Craveiro WA. Perfil das superfícies plantares de atletas amadores de corrida de rua em Brasília [dissertation]. Brasília, DF: Universidade Paulista, 2009.20 p.

14. The R Project for Statistical Computing [Internet]. [Vienna]: The R Foundation [cited 2020 Mar 23]. Available from: https://www.r-project.org/

15. Fernández de Retana P, Álvarez F, Viladot R. Subtalar arthroereisis in pediatric flatfoot reconstruction. Foot Ankle Clin. 2010;15(2):323-35.

16. Dana C, Péjin Z, Cadilhac C, Wicart P, Glorion C, Aurégan JC. Long-term results of the "horseman" procedure for severe idiopathic flatfoot in children: a retrospective analysis of 41 consecutive cases with mean 8.9 year duration of follow-up. J Foot Ankle Surg. 2019;58(1):10-6.

17. Kelikian A, Mosca V, Schoenhaus HD, Winson I, Weil L Jr. When to operate on pediatric flatfoot. Foot Ankle Spec. 2011;4(2):112-9.

18. Metcalfe SA, Bowling FL, Reeves ND. Subtalar joint arthroereisis in the management of pediatric flexible flatfoot: a critical review of the literature. Foot Ankle Int. 2011;32(12):1127-39.

19. Faldini C, Mazzotti A, Panciera A, Persiani V, Pardo F, Perna F, et al. Patient-perceived outcomes after subtalar arthroereisis with bioabsorbable implants for flexible flatfoot in growing age: a 4-year follow-up study. Eur J Orthop Surg Traumatol. 2018;28(4):707-12.

20. Zaret DI, Myerson MS. Arthroereisis of the subtalar joint. Foot Ankle Clin 2003;8(3):605-17. 